\title{
Experimental Design on Laminated Veneer Lumber Fiber Reinforced Composite: Processing Parameters and Its Durability
}

\author{
Utai Meekum $^{1,2}$ and Yumatorn Mingmongkol ${ }^{1,2}$ \\ 1. School of Polymer Engineering, Institute of Engineering, Suranaree University of Technology, Nakorn Ratchasima 30000 , \\ Thailand \\ 2. Centre of Excellent for Petroleum, Petrochemical and Advanced Material, Chulalongkorn University, Bangkok 10330, Thailand
}

\begin{abstract}
The investigating of the hot press process parameters on the flexural properties of LVL (Laminated Veneer Lumber) reinforced composites derived from rubber wood veneer reinforced with fiber glass woven and epoxy adhesive were performed via the DOE (design of experimental) approach. It was discovered that pressure was the most significantly and negatively effect on the product properties. Enhancing in the mechanical properties was related to decrease the processing pressure. Beside, press time was also significantly and positively effect. Although time was not clearly reflect from the mechanical results, but it was detected from the ANOVA (analysis of variance) results. The mechanical properties were increased with increasing compression time. From the results, the optimal condition to maximize mechanical properties was assumed at low pressure, 15 bars, low temperature, $70^{\circ} \mathrm{C}$, and long time, 60 mins. The durability testing including screw nail withdrawal strength, water absorption, and termite resistance of LVL reinforced composite were also studied. The results are shown that the LVL wood has superior properties when compare with solid woods. It was found the withdrawal strength of LVL reinforce composite was higher than the solid woods. As expected that solid woods, except eucalyptus, had low water absorption resistance as it more hygroscopic corresponded to LVL reinforced wood. Also solid woods, except teak, had low resistance to termite attack. Therefore, LVL reinforced was the best candidate by mean of durability properties compared to solid wood.
\end{abstract}

Key words: DOE, LVL reinforced wood, processing parameters, durability testing.

\section{Introduction}

The engineered wood is one of the reliable materials. It has been successfully used in variety of applications such as construction materials. Normally, they are produced from wood, adhesive and fiber reinforcement that are bonded together by pressure and heat. Thus, the properties of the product are depended on raw materials, wood, adhesive, and fiber reinforcement, and processing conditions. The mechanical properties and durability are the prime interests for most of applications. LVL (laminated veneer lumber) is one of the most common engineered woods. There have been

Corresponding author: Utai Meekum, $\mathrm{PhD}$, associate professor, research fields: polymer and composite processing. E-mail: umsut@g.sut.ac.th. a lot of publications reported on the improvement of mechanical and durability of the wood [1-3]. The veneers or any mean of wood sheets are important not only their strength but the abundant and diversifying and modification for value addition are greatly interests [4-6]. Adhesives that play the important role for consolidating the wood constituent together have been also investigated and published [7-10]. The reinforcement, mainly synthetic, in the form of unidirectional roving or fabric that used to further strengthen the engineered wood has been explored in recent year [11-14].

In this report, the LVL constructed base on veneer rubber wood, epoxy adhesive and fiber glass woven is presented. The rubber plantation in Southeast Asia region is one of the most common and important 
commercial crops. Furniture industries using aged rubber tree wood are rapidly growing. Diversify and further increasing the value and application of this wood is wildly attention. Epoxy adhesive not only improves the moisture absorption and hence durability of the wood but also superiorly increases the bonding strength and insect attraction. Fibre glass woven as the common and inexpensive reinforcement for the engineered wood is used to expand the limitation of the material by mean of the mechanical characteristics and applications point of view. In previous reports, the studies of wood constituents and their surface enhancement were presented $[15,16]$. In this manuscript, the processing parameters used to manufacture the LVL and the durability testing of the wood product will be discussed by mean of statistical DOE approach and actual experiment practice, respectively.

\section{Experimental Procedures}

\subsection{DOE (Design of Experiment)}

The $2^{\mathrm{k}}$ factorial experimental design was used to analyze the significant effect of processing parameters, pressure (A), temperature (B) and time (C), for manufacturing the LVL composite by hot compression. The mechanical properties by mean of flexural and the specific flexure were evaluated as experimental responds. Table 1 is shown the parameters and their set levels, high (+) and low (-), for designing the DOE.
Each parameter level is divided into two sub levels. By using the $2^{\mathrm{k}}$ factorial design with $\mathrm{k}=3$, the design matrix for the DOE is shown in Table 2. Therefore, total of eight runs are tested.

The influence of processing parameters on the flexural properties of the LVL reinforced composite were examined by using the multi ANOVA (analysis of variance) with the level of significant $(\alpha)$ of 0.05 or $95 \%$ confidential. Calculation of the significant effect of the respond data on the design parameter was performed through the Design Expert ${ }^{\mathrm{TM}}$ commercial software.

\subsection{Sample Preparation and Mechanical Testing}

The main materials used for construction the LVL composite can be classified into three categories: (1) the wood veneers, (2) reinforcement materials, the fiber glass woven, and (3) the in house formulated epoxy adhesive [17]. The veneer rubber woods from local farm with an average thickness of $2.5 \mathrm{~mm}$ and $150 \times 150 \mathrm{~mm}$ were alternately stacked as core. For machine sliced young teak veneer wood, around 15 years old tree, having average thickness of $0.5 \mathrm{~mm}$ was used to overlay on the faces of LVL board. The veneers

Table 1 The parameters and the levels for DOE.

\begin{tabular}{lll}
\hline Factor & Low Level $(-)$ & High Level $(+)$ \\
\hline Pressure (A) (bar) & 15 and 25 & 35 and 45 \\
Temperature (B) $\left({ }^{\circ} \mathrm{C}\right)$ & 70 and 80 & 90 and 100 \\
Time (C) (mins) & 30 and 40 & 50 and 60 \\
\hline
\end{tabular}

Table 2 The design matrix for three processing parameters $(k=3)$.

\begin{tabular}{lllllll}
\hline \multirow{2}{*}{ Run } & \multicolumn{3}{c}{ Design Code } & \multicolumn{3}{c}{ Compression Conditions } \\
\cline { 2 - 7 } & A & B & C & Pressure (bar) & Temperature $\left({ }^{\circ} \mathrm{C}\right)$ & Time (mins) \\
\hline P1 & + & + & + & 35 & 90 & 50 \\
P2 & + & + & - & 45 & 100 & 30 \\
P3 & + & - & + & 35 & 70 & 60 \\
P4 & + & - & - & 45 & 80 & 40 \\
P5 & - & + & + & 15 & 90 & 50 \\
P6 & - & - & - & 25 & 100 & 30 \\
P7 & - & - & + & 15 & 70 & 60 \\
P8 & - & - & - & 25 & 80 & 40 \\
\hline
\end{tabular}


were oven dried at $105^{\circ} \mathrm{C}$ for several hours to reduce moisture content to $6-14 \%$. The plain woven E-glass fabric reinforcements were, LT800-E with area weight density of $821 \pm 3 \% \mathrm{~g} / \mathrm{m}^{2}$. The in house room temperature epoxy system was consisted of Bisphenol A based epoxy resin and amine mixed with silane curing agent. All the chemicals were commercially supplied and they were used as received.

The LVL reinforced composites with 14 layers of veneers were produced to required thickness approx. $38 \mathrm{~mm}$. The woven fibers were placed between layers of wood sheet. Teak veneers were faced on both sides. The woven fibers and wood veneers were throughout impregnated with adhesive by using hand lay-up process. The LVL samples were cured at the designed processing parameters in compression press by placing sample into a rectangular preheated two plate metal mold. After completely cured, it was demolded and undergone post curing at $80^{\circ} \mathrm{C}$ for five hours in the oven. The LVL reinforced composites test specimen were cut by sawing machine into the require dimension. The samples were polished using sanding paper.

ASTM 790 was followed for the flexural properties testing. The three point bending fixture and Instron ${ }^{\mathrm{TM}}$ 5569 universal testing machine with $50 \mathrm{kN}$ load cell were employed. The LVL sample was placed for bending load at span length of $100 \mathrm{~mm}$. Flexural specimens with an average geometry of $130 \mathrm{~mm}$ length, $25 \mathrm{~mm}$ width, and $38 \mathrm{~mm}$ thickness, as shown in Fig. 1, was bended to failure under constant displacement electrically controlled rate of $5.5 \mathrm{~mm} / \mathrm{min}$. Five specimens were needed for each test. The flexural strength, modulus, and toughness were calculated and reported. The toughness of LVL was calculated by integrating the area under stress-strain curve of flexural testing and recorded as $\mathrm{kJ} / \mathrm{m}^{2}$. The specific strength was acquired by dividing the strength by the sample density was also recorded.

\subsection{Durability Testing}

The Instron ${ }^{\mathrm{TM}} 5569$ Universal testing machine with $50 \mathrm{kN}$ load cell and modified jaw grip was used to performed the screw nail pull-out testing. According to the standard test, the LVL reinforced composites samples with an average geometry of $130 \mathrm{~mm}$ length, $25 \mathrm{~mm}$ width, and $38 \mathrm{~mm}$ thickness were employed. The screw nail with $4.1 \mathrm{~mm}$ outer diameter and $50 \mathrm{~mm}$ in length was fitted into the pre-holed, using drills diameter of $3.3 \mathrm{~mm}$, with the hole depth of $9 \mathrm{~mm}$. The hole obtained was $70 \%$ of nail screw root diameter. The screw was placed in the radial direction of specimen. The screw was forced further using the screw driver until the total depth of $25 \mathrm{~mm}$ was reached. The specimens were fixed onto the testing machine. During the test, pulling speed at $2.5 \mathrm{~mm} / \mathrm{min}$ was applied until the screw was completely separated apart from specimens or until the screw was broken. For each of the test, average value obtained from three individual samples was recorded. The screw withdrawal strength

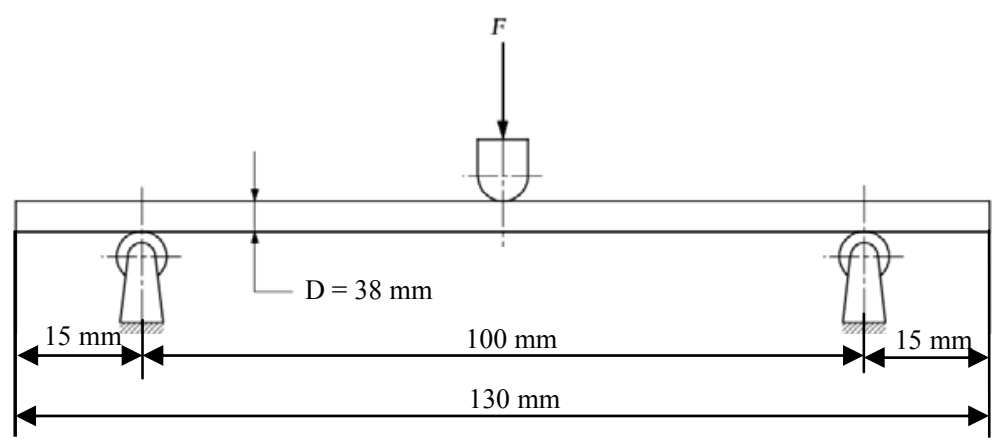

Fig. 1 Flexural testing set up. 
was computed according to the Eq. (1) given below:

$$
\sigma_{s}=\frac{\mathbf{P}_{\max }}{2 \pi \mathbf{h}}
$$

where, $\sigma_{\mathrm{s}}=$ screw withdrawal strength, $\mathrm{N} / \mathrm{mm}^{2}, P_{\text {max }}=$ the maximum load, $N$ and $2 \pi \boldsymbol{r h}=$ the surface area of the screw exposed to friction, $\mathrm{mm}^{2}$.

The water absorption of the LVL reinforced composite was evaluated by preparing three specimens with an average geometry of $65 \mathrm{~mm}$ in length, $25 \mathrm{~mm}$ in width, and $38 \mathrm{~mm}$ in thickness. The specimens were weighed before submersion in water bath. In order to accelerate the water absorption process, the samples were immersed in hot water at $70^{\circ} \mathrm{C}$ and then sampling in every 24 hours, until the constant weight were found. For this study, one week of incubation was required. The water absorption percentage of the sample was calculated by using the following equation:

$$
A=\frac{\mathbf{W}_{\mathbf{i}}-\mathbf{W}_{\mathbf{0}}}{\mathbf{W}_{\mathbf{0}}} \times 100
$$

where, $\mathrm{A}=$ water absorption, $\%$;

$\mathrm{W}_{\mathrm{o}}=$ Weight before submersion, $\mathrm{g}$;

$\mathrm{W}_{\mathrm{i}}=$ Weight on the measurement after submersion, g.

Three specimens of the LVL reinforced composite with an average geometry of $65 \mathrm{~mm}$ length, $25 \mathrm{~mm}$ width, and $38 \mathrm{~mm}$ thickness were obtained for termite resistance testing. The specimens were weighed before burying in soil. The specimens were weighed every two weeks for three months to monitor the weight loss.
The testing site was located at Suranaree University of Technology where the native species of termite was observed. There was no biological termite screening on this test. The percentage of WL (weight loss) was calculated as the same manner as water absorption testing. The visual observation by mean of photography on specimen before and after test was also reviewed. Solid wood including teak, rubber wood, eucalyptus, and local hardwood with same dimensions were also examined to provide the reference values for all durability investigations.

\section{Results and Discussion}

Table 3 shows the flexural and specific values by mean of strength, modulus and toughness of LVL reinforced composites derived from difference processing parameters as designed by $2^{\mathrm{k}}$ DOE given in Table 2. It is found that the maximum strength at $58.8 \pm$ 3.5 $\mathrm{MPa}$ is observed in the $\mathrm{P} 7$ sample. The lowest strength, 34.1 $\pm 2.4 \mathrm{MPa}$ is seen in the P2. The P5 and the $\mathrm{P} 4$ conditions reveal the maximum and minimum modulus at $944.6 \pm 85.6 \mathrm{MPa}$ and $557.3 \pm 293.5$, respectively. Within the standard deviation, the P5 and $\mathrm{P} 1$ indicate the maximum and minimum toughness strength at $144.0 \pm 39.9 \mathrm{~kJ} / \mathrm{m}^{2}$ and $81.0 \pm 11.0 \mathrm{~kJ} / \mathrm{m}^{2}$, respectively. The similar trend is also resumed for the calculated specific values as concluded in Table 3.

\begin{tabular}{|c|c|c|c|c|c|c|}
\hline \multirow[b]{2}{*}{ Run } & \multicolumn{3}{|c|}{ Flexural Properties } & \multicolumn{3}{|c|}{ Specific Flexural Properties } \\
\hline & $\begin{array}{l}\text { Strength } \\
\text { (MPa) }\end{array}$ & $\begin{array}{l}\text { Modulus } \\
(\mathrm{MPa})\end{array}$ & $\begin{array}{l}\text { Toughness } \\
\left(\mathrm{kJ} / \mathrm{m}^{2}\right)\end{array}$ & $\begin{array}{l}\text { Specific } \\
\text { Strength } \\
\left(\frac{\mathrm{kPa}}{\mathrm{kg} / \mathrm{m}^{3}}\right)\end{array}$ & $\begin{array}{l}\text { Specific } \\
\text { Modulus } \\
\left(\frac{\mathrm{kPa}}{\mathrm{kg} / \mathrm{m}^{3}}\right)\end{array}$ & $\begin{array}{l}\text { Specific } \\
\text { Toughness } \\
\left(\frac{\left(\mathrm{J} / \mathrm{m}^{2}\right)}{\mathrm{kg} / \mathrm{m}^{3}}\right)\end{array}$ \\
\hline$\overline{\mathrm{P} 1}$ & $38.0 \pm 4.2$ & $742.1 \pm 43.4$ & $81.0 \pm 11.0$ & $42.4 \pm 5.5$ & $824.6 \pm 34.1$ & $90.3 \pm 14.3$ \\
\hline $\mathrm{P} 2$ & $34.0 \pm 2.4$ & $812.8 \pm 50.6$ & $94.2 \pm 34.3$ & $37.8 \pm 2.9$ & $901.2 \pm 62.3$ & $104.3 \pm 37.9$ \\
\hline P3 & $43.1 \pm 14.8$ & $689.6 \pm 144.8$ & $109.7 \pm 57.9$ & $46.5 \pm 15.8$ & $741.8 \pm 143.0$ & $118.9 \pm 63.7$ \\
\hline P4 & $35.7 \pm 13.8$ & $557.3 \pm 293.5$ & $114.4 \pm 39.9$ & $39.4 \pm 14.1$ & $612.9 \pm 306.2$ & $127.0 \pm 44.1$ \\
\hline P5 & $54.5 \pm 6.0$ & $944.6 \pm 85.6$ & $144.0 \pm 39.9$ & $59.6 \pm 4.9$ & $1,033.9 \pm 67.6$ & $157.6 \pm 21.2$ \\
\hline P6 & $51.2 \pm 8.5$ & $791.7 \pm 47.1$ & $109.2 \pm 22.2$ & $59.4 \pm 8.5$ & $920.7 \pm 43.1$ & $126.6 \pm 22.5$ \\
\hline P7 & $58.8 \pm 3.5$ & $906.1 \pm 35.1$ & $141.7 \pm 13.6$ & $65.2 \pm 4.1$ & $1004.9 \pm 52.1$ & $156.9 \pm 12.8$ \\
\hline P8 & $46.7 \pm 13.3$ & $688.6 \pm 84.9$ & $129.9 \pm 51.6$ & $52.1 \pm 15.3$ & $768.2 \pm 110.0$ & $145.0 \pm 58.7$ \\
\hline
\end{tabular}

Table 3 Flexural and specific Flexural properties of LVL composites, respectively. 
The three factors DOE, pressure, temperature and time and its analysis of the effect response values in respect to flexural properties by half-normal plot and pareto charts are illustrated in Figs. 2a-2d, respectively. Tables $4 \mathrm{a}$ and $3 \mathrm{~b}$ summarize the ANOVA test results of flexural and specific flexural responds obtained from the DOE of LVL composite. It reveals that the calculated p-values are less than the critical values, 0.05 , for factor $\mathrm{A}$ and $\mathrm{C}$ which are negative (-) and positive $(+)$ effects, respectively. They will be assessed that the highest values of flexural strength and the specific ones, can be obtained where compression pressure is set at low level (A-) and the cure time at high level $(\mathrm{C}+)$. These can be seen in the main effects plots in Figs. 2a-2d. It concludes that using low pressure and long period of time in curing process will increase the strength. Vice versa, the inferior properties

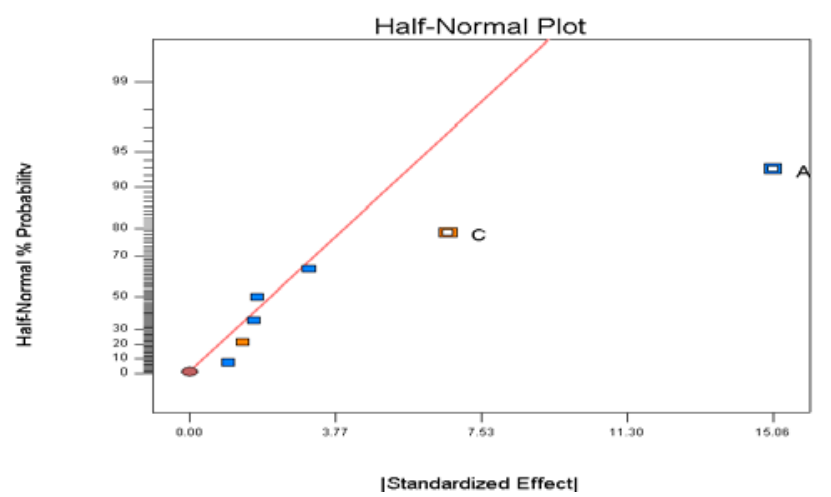

(a)

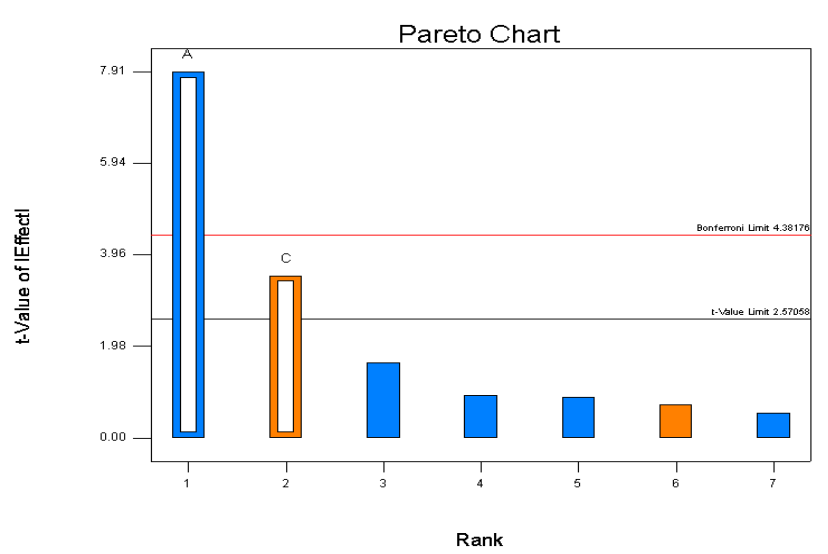

(c) will be obviously seen when the pressure is increased to high magnitude and the time is minimized. Consequently, the effects of compression pressure (A) and time $(\mathrm{C})$ on the flexural strength and specific flexural strength is statistically significant. Further analysis methods by the similar manners were found that there is no significant effect of processing factors on modulus. However, the pressure, factor A, is the most significantly effect on the toughness properties where the calculated p-value is less than 0.05 , In contrast, the toughness properties will dramatically decrease when increasing the pressing pressure. According to the statistical approach by mean of DOE analysis, the conclusion can be made that the optimal process parameters setting which maximize the mechanical properties of LVL reinforced composites derived from rubber wood veneers and using epoxy as

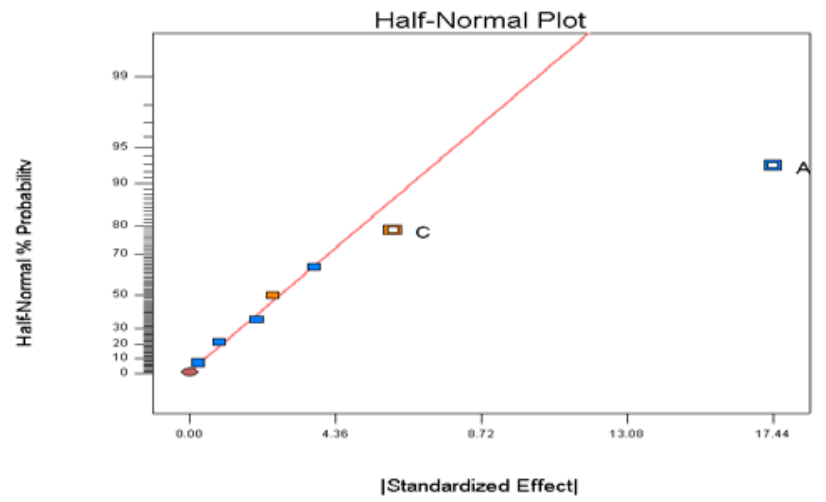

(b)

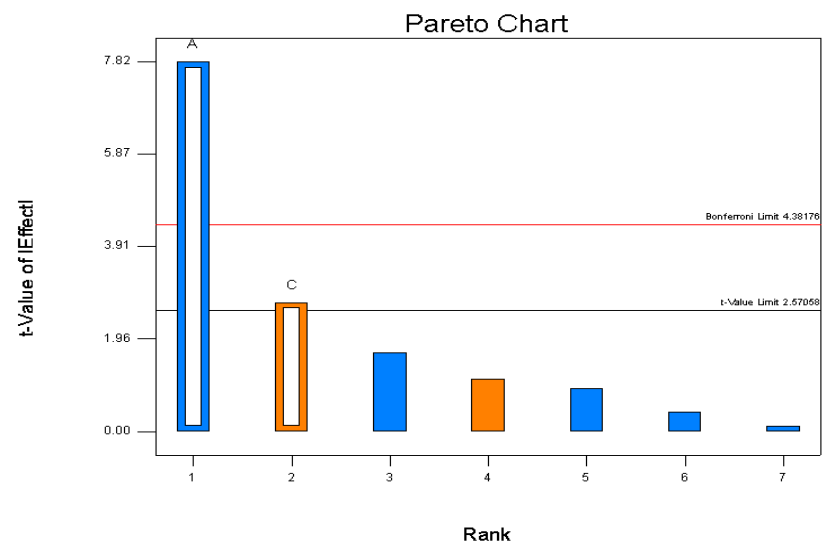

(d)

Fig. 2 Half normal plots of: (a) flexural; (b) specific flexural properties, and pareto chart of: (c) flexural; (d) specific flexural properties of LVL composite. 
Table 4 ANOVA test results of (a) flexural and (b) specific flexural properties.

(a)

\begin{tabular}{llllll}
\hline Source & $\begin{array}{l}\text { Sum of } \\
\text { Squares }\end{array}$ & df & $\begin{array}{l}\text { Mean } \\
\text { Square }\end{array}$ & F-value & p-value \\
\hline A & 453.82 & 1 & 453.82 & 62.63 & 0.0005 \\
C & 89.10 & 1 & 89.10 & 12.30 & 0.0172 \\
Residual & 36.23 & 5 & 7.25 & & \\
Cor total & 579.15 & 7 & & & \\
\hline
\end{tabular}

(b)

\begin{tabular}{llllll}
\hline Source & $\begin{array}{l}\text { Sum of } \\
\text { Squares }\end{array}$ & df & $\begin{array}{l}\text { Mean } \\
\text { Square }\end{array}$ & F-value & p-value \\
\hline A & 618.05 & 1 & 618.05 & 58.50 & 0.0006 \\
C & 77.34 & 1 & 77.34 & 7.32 & 0.0425 \\
Residual & 52.83 & 5 & 10.57 & & \\
Cor Total & 748.22 & 7 & & & \\
\hline
\end{tabular}

adhesive are at low level pressure, 15 bar, low level temperature, $70^{\circ} \mathrm{C}$, and high level of compression time, 60 mins.

Table 5 summarizes the mechanical properties including the specific values of the best LVL composite prepared by the optimal curing condition compared to those solid woods including teak, rubber, eucalyptus and hardwood. From the results assess that flexural modulus of the LVL composite are obviously higher than the solid woods. In case of flexural strength, it slightly higher than those of solid woods. In contras, flexural toughness of the LVL composite is found to be lower than the solid woods.

Table 6 presents the withdrawal strength and average density results of solid wood and LVL reinforced composite. During the test it was observed that the screw attached to LVL was failed before the competition of withdrew process. So, the figure shown is not the actual withdraw strength of LVL. The true value would be higher than that the reported. As the results, the highest value at $16.5 \pm 1.1 \mathrm{~N} / \mathrm{mm}^{2}$ of withdrawal strength is evidenced for LVL reinforced composite. The strength for eucalyptus, hardwood, rubber and teak woods are consequently lower. The lowest withdrawal strength is observed for teak and rubber woods. By dividing the strength with the density to obtain the specific values, Fig. 3 is the plot of the specific figures and wood types. The calculated results show that the specific value of teak and rubber wood are higher that the others. However, it can not really compare with LVL wood due to the fact that the actual strength of this wood is higher than that reported. General conclusion can be drawn at this stage of work that the withdrawing strengths of LVL are probable higher than the solid woods.

The tendency of wood to absorb moisture is very important on durability properties of wood including mechanical strength, appearance, and dimension stability. According to moisture content changing relate to expansion or shrinkage of timber warps and twists then it is lower strength. Fig. 4 is the plot of water absorption with time of the solid woods and LVL reinforced composite conducted at $70^{\circ} \mathrm{C}$ for a week. From the results, it is found that the lowest water absorption (\%) is clearly indicated for the LVL composite. Therefore, the LVL reinforced exhibits the better water resistance compared to those solid woods.

Table 5 Summary of the properties of the LVL composite and solid woods.

\begin{tabular}{lllllll}
\hline & \multicolumn{3}{c}{ Flexural properties } \\
\cline { 2 - 7 } $\begin{array}{l}\text { Wood } \\
\text { Type }\end{array}$ & $\begin{array}{l}\text { Strength } \\
(\mathrm{MPa})\end{array}$ & $\begin{array}{l}\text { Modulus } \\
(\mathrm{MPa})\end{array}$ & $\begin{array}{l}\text { Toughness } \\
\left(\mathrm{kJ} / \mathrm{m}^{2}\right)\end{array}$ & $\begin{array}{l}\text { Specific } \\
\text { Strength }\end{array}$ & $\begin{array}{l}\text { Specific } \\
\text { Modulus }\end{array}$ & $\begin{array}{l}\text { Specific } \\
\text { Toughness } \\
\end{array}$ \\
\hline Teak & $56.5 \pm 4.0$ & $336.1 \pm 57.6$ & $382.7 \pm 26.3$ & $79.3 \pm 3.4$ & $468.3 \pm 29.5$ & $542.6 \pm 95.8$ \\
Rubber & $43.8 \pm 5.9$ & $250.4 \pm 44.2$ & $329.6 \pm 29.6$ & $69.0 \pm 5.5$ & $393.5 \pm 47.1$ & $519.8 \pm 28.6$ \\
Eucalyptus & $50.4 \pm 14.5$ & $368.5 \pm 143.3$ & $285.6 \pm 102.0$ & $55.7 \pm 11.0$ & $405.2 \pm 131.4$ & $314.7 \pm 83.1$ \\
Hardwood & $50.2 \pm 2.7$ & $303.6 \pm 7.3$ & $383.4 \pm 47.9$ & $74.5 \pm 3.0$ & $451.6 \pm 18.0$ & $569.4 \pm 60.5$ \\
LVL composite & $58.8 \pm 3.5$ & $906.1 \pm 35.1$ & $141.7 \pm 13.6$ & $64.7 \pm 3.3$ & $996.2 \pm 26.5$ & $155.9 \pm 15.4$ \\
\hline
\end{tabular}


Table 6 The screw withdrawal stregnth of woods.

\begin{tabular}{lll}
\hline Materials & $\begin{array}{l}\text { Density } \\
\left(\mathrm{kg} / \mathrm{m}^{3}\right)\end{array}$ & $\begin{array}{l}\text { Withdrawal } \\
\text { strength }\left(\mathrm{N} / \mathrm{mm}^{2}\right)\end{array}$ \\
\hline Teak wood & $631.6 \pm 41.9$ & $12.9 \pm 0.3$ \\
Rubber wood & $581.8 \pm 50.2$ & $12.9 \pm 0.5$ \\
Eucalyptus wood & $849.6 \pm 62.9$ & $15.1 \pm 1.7$ \\
Hardwood wood & $757.7 \pm 20.5$ & $14.2 \pm 0.5$ \\
LVL composite & $855.5 \pm 23.2$ & $16.5 \pm 1.1^{*}$ \\
\hline
\end{tabular}

*screw were fail beyond this point

As expected, the water absorption value is higher for the solid woods, especially in the rubber, compared with the LVL. Commercially, rubber wood had it limitation for outdoor applications as it shows the highest water uptake, on the other word, the lowest in water resistance. It always twists bends and finally cracks. In case of eucalyptus wood shows the lower water absorption. This may be caused from the hydrophobic oily substance in the wood fiber.

The termites or white ants are one of the most important groups of bio organism known to destroy cellulosic materials especially wood. Termites breaks down the internal structure of wood and thereby its mechanical functionality is reduced. Fig. 5 presents the calculated weight loss resulted from solid woods and the LVL. As expected, the solid woods, except teak, shows rapid \% weight loss, indicating that these solid woods were attacked or destroyed by termite. This statement is visibly evidenced in the following photographs as presented in Fig. 6. As commonly known for its outstanding characteristic, teak wood shows no attack by termite within three months. It is certified as "national durability" or alternatively "decay resistance" wood. LVL reinforced composite shows lower in weight loss percentage. Meaning that, it is better in termite resistance. This superior characteristic of the LVL may be explained by that the important role of epoxy adhesive act as the protective surface of the wood from termite attack.

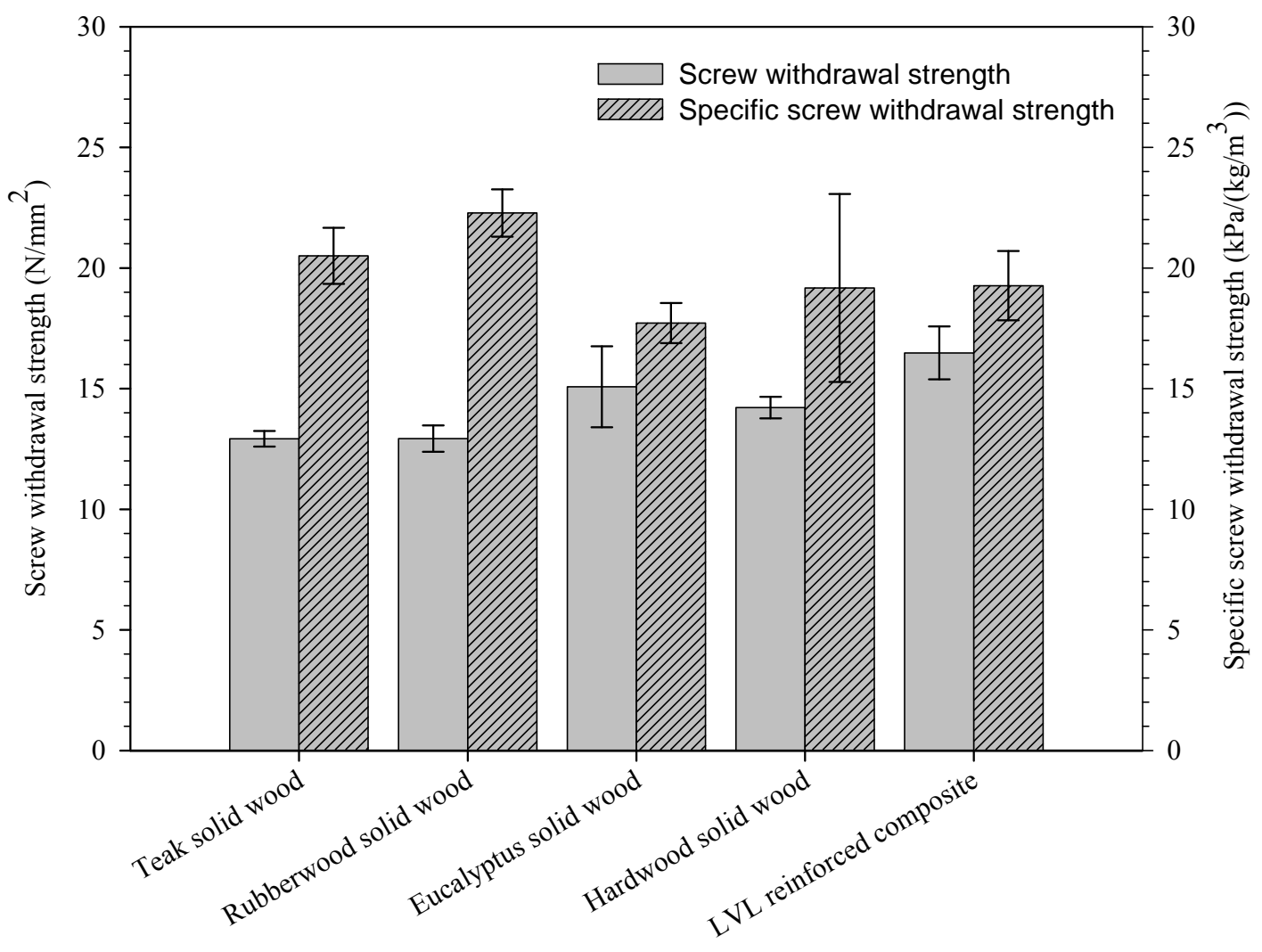

Wood Type

Fig. 3 The withdrawal strength and its calculated specific strength of woods. 


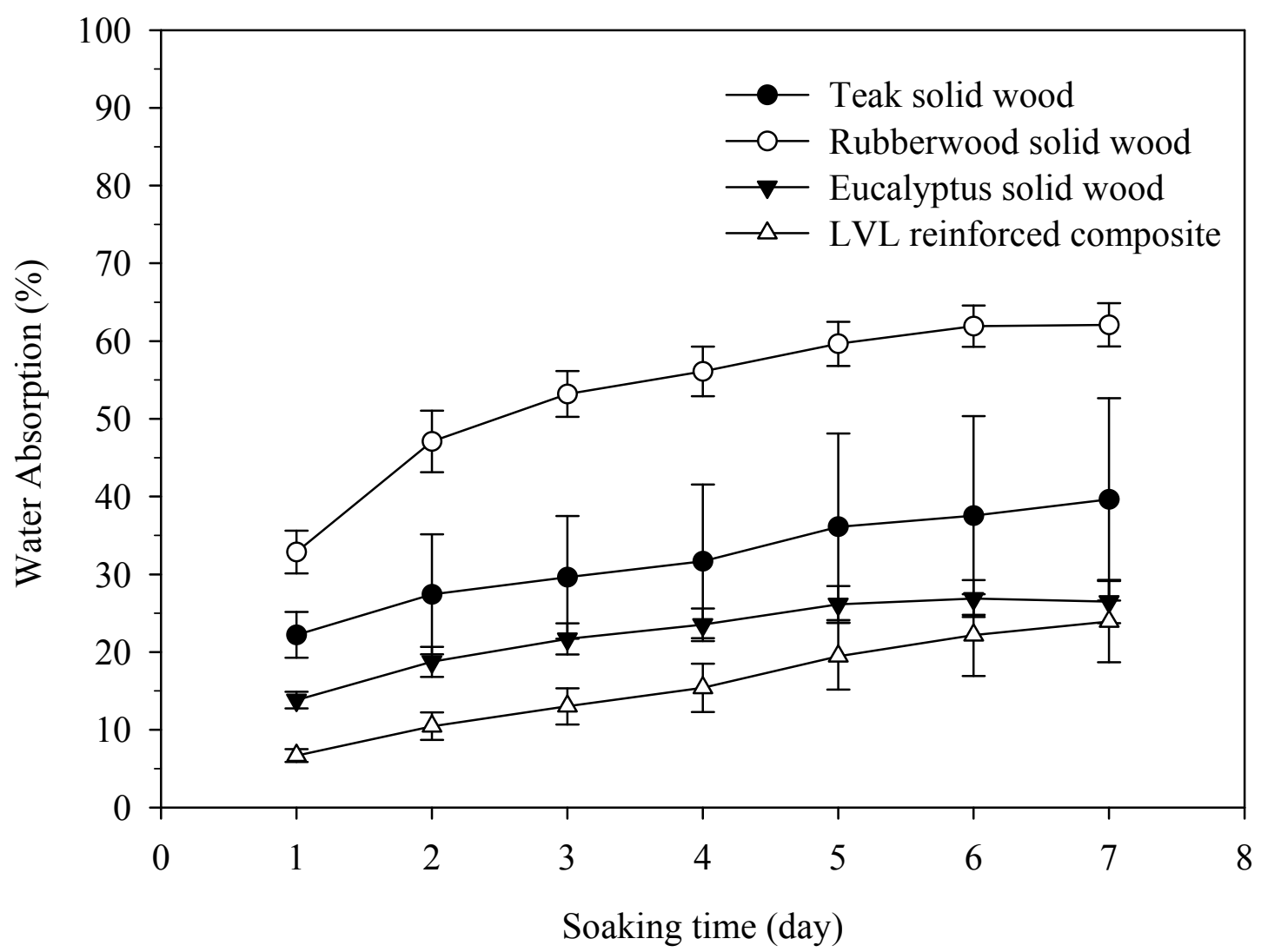

Fig. 4 Water absorption with soaking time of the solid woods and LVL composite.

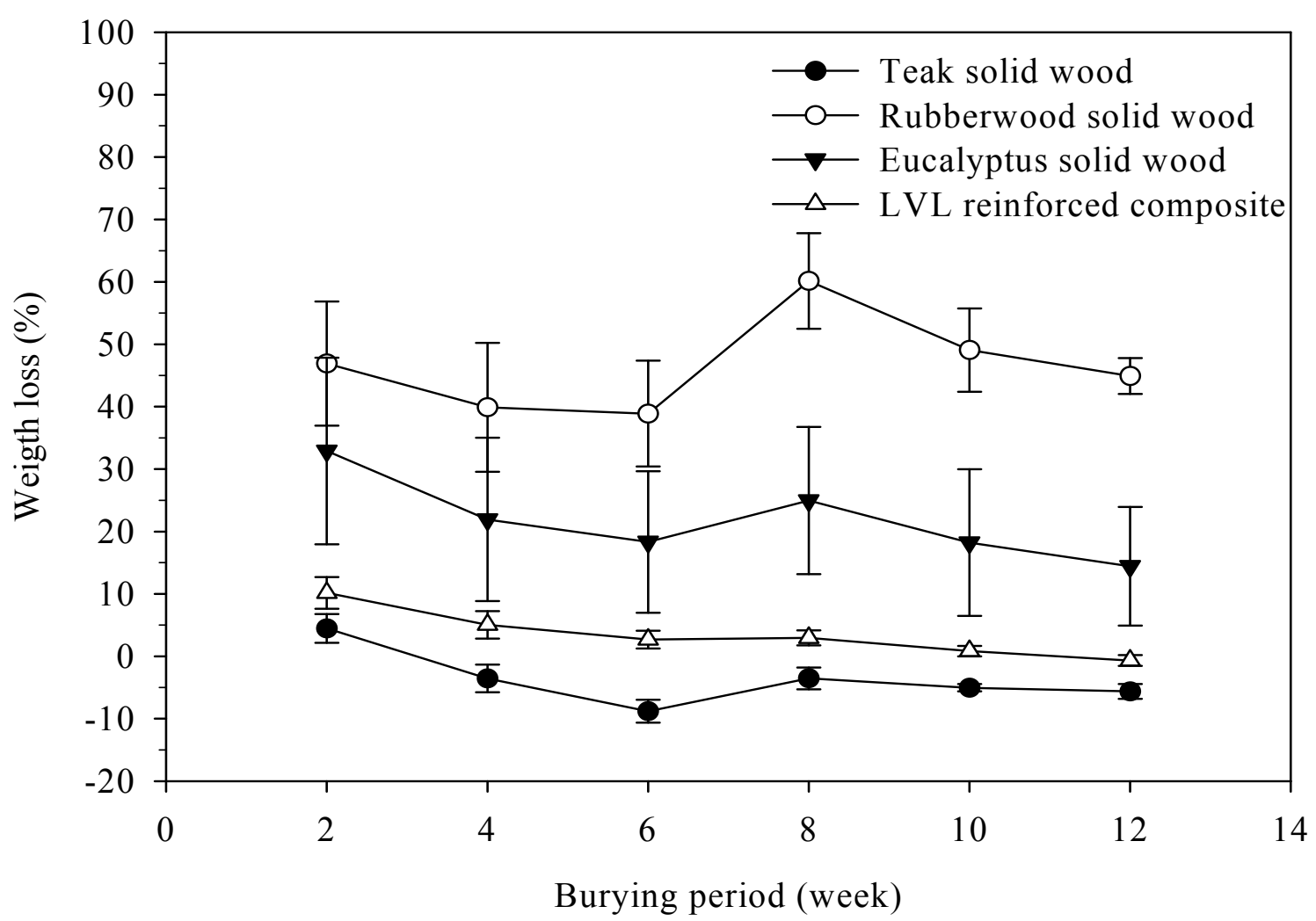

Fig. 5 Weigh loss resulted from termite attack. 


\begin{tabular}{|c|c|c|}
\hline Wood Type & Before & After \\
\hline Teak wood & & \\
\hline Rubber wood & & \\
\hline Eucalyptus wood & & \\
\hline LVL composite & & \\
\hline
\end{tabular}

Fig. 6 The physical appearance of woods before and after burying in soil for 12 weeks.

\section{Conclusions}

Investigating of the effect hot press process parameters on the flexural properties of LVL reinforced composites, it was discovered that pressure was the most significantly and negatively effect on the product properties. Enhancing in the mechanical properties was related to decrease the processing pressure. Beside, press time was also significantly and positively effect. Although time was not clearly reflect from the mechanical results, but it was detected from the ANOVA results. The mechanical properties were increased with increasing compression time. From the results, the optimal condition to maximize mechanical properties was assumed at low pressure, 15 bars, low temperature, $70^{\circ} \mathrm{C}$, and long time, 60 mins. Within the research limitation including material used, specimen, magnitude of curing parameters and so on, the durability including screw nail withdrawal strength, water absorption, and termite resistance of LVL reinforced composite were superior when compare with solid woods. It was found the withdrawal strength of LVL reinforce composite was higher than the solid woods. As expected that solid woods, except eucalyptus, had low water absorption resistance as it more hygroscopic corresponded to LVL reinforced wood. Also solid woods, except teak, had low resistance to termite attack. Therefore, LVL reinforced 
was the best candidate by mean of durability properties compared to solid wood.

\section{References}

[1] I. Aydin, G. Colakoglu, S. Colak and C. Demirkir, Effects of moisture content on formaldehyde emission and mechanical properties of plywood, Building and Environment 41 (2006) 1311-1316.

[2] S. Colak, G. Colakoglu and I. Aydin, Effects of logs steaming veneer drying and aging on the mechanical properties of laminated veneer lumber (LVL), Building and Environment 42 (2007) 93-98.

[3] D. Toksoy, G. Colakoglu and I. Aydin, Technological and economic comparison of the usage of beech and alder wood in plywood and laminated veneer lumber manufacturing, Building and Environment 41 (2006) 872-876.

[4] A. Andre, Fibers for strengthening of timber structures, Ph.D. thesis, Lulea University, Sweden, 2006.

[5] G. Celebi and M. Kilic, Nail and screw withdrawal strength of laminated veneer lumber made up hardwood and softwood layers, Construction and Building Materials 21 (2007) 894-900.

[6] F. Feng, F. C. Bao and F. Fu, End use selection of plantation poplar: solid wood or laminated veneer lumber (LVL), Sci. Silvae Sinicae 35 (1999) 58-65.

[7] R. F. Blomquist and C. B. Vick, Adhesives for Building Construction (2nd ed.), U.S. Government, Wisconsin, 1997.

[8] S. Kim and H. J. Kim, Study of miscibility of melamine-formaldehyde resin and poly (vinyl acetate) blends for use as adhesives in engineered flooring, J. Adhesion Sci. Technol. 20 (2006) 209-219.
[9] L. Qiao, A. J. Easteal and C. J. Bolt, Improvement of the water resistance of poly (vinyl acetate) emulsion wood adhesive, Pigm. Resin Technol. 29 (2000) 152-158.

[10] A. Nadir, Z. Candan and S. Hiziroglu, Physical and mechanical properties of cardboard panels made from used beverage carton with veneer overlay, Materials and Design 29 (2008) 1897-1903.

[11] P. Alam, M. P. Ansell and D. Smedley, Mechanical repair of timber beams fractured in flexure using bonded-in reinforcements, Composites Part B: Engineering 40 (2009) 95-106.

[12] K. C. Johns and S. Lacroix, Composite reinforcement of timber in bending, Canadian Journal of Civil Engineering 27 (2000) 899-906.

[13] A. Pirvu, D. J. Gardner and R. Lopez-Anido, Carbon fiber-vinyl ester composite reinforcement of wood using the VARTM/SCRIMP fabrication process, Composites: Part A 35 (2004) 1257-1265.

[14] A. Borri, M. Corradi and A. Grazini, A Method for Flexural Reinforcement of Old Wood Beams with CFPR Materials, Composites: Part B 36 (2005) 143-153.

[15] U. Meekum and Y. Mingmonkol, Experimental design on laminated veneer lumber fiber composite: surface enhancement, in: 5th International Conference on Times of Polymers (TOP) \& Composite, Ischia Italy, June 20-23, 2010.

[16] U. Meekum, Experimental design on multi layers of LVL fiber reinforced wood composite using bagasse as core structure, in: the 5th International Conference on FRP Composites in Civil Engineering (CICE 2010), Beijing, China, Sep. 27-29, 2010.

[17] N. Wanaporn, Prepreg formulation for windsurf and surfboard manufacturing, M.S. Thesis, Suranaree University of Technology, Thailand, 2005. 